\title{
Realismo crítico mestizo: una visión de México desde el enfoque estratégico-relacional'
}

Héctor Cuadra Montiel²

\section{Resumen}

Este artículo comienza con un breve análisis de las características fundamentales del Estado mexicano contemporáneo y su régimen semi-autoritario de gobierno. Después pasa a una discusión de las posiciones críticas realistas y las características que informan el enfoque estratégicorelacional (SRA). Se presta atención a las interacciones sociales y las relaciones causales que permiten al SRA trazar pautas de evolución y destacar los procesos de transformación. Dado que los tipos ideales sirven para destacar las características clave en fenómenos específicos, procesos y actores, algunas características de los tipos ideales del Estado y de la transición de un tipo a otro son también discutidas. En particular, se presta atención al Estado Nacional de Bienestar Keynesiano (KWNS) y al Régimen Post-nacional Schumpeteriano Laboral (SWPR), tipos ideales elaborados por Jessop. Para ello se sostiene que las características específicas de estos tipos ideales podrían ser de gran ayuda en la ampliación del debate sobre la reestructuración económica y las reformas políticas en países como México. Por otra parte, el enfoque SRA permite adentrarse a las características endógenas del cambio social y también destaca la importancia del trabajo en red para una agenda estratégica. La dinámica no-estática de los procesos de cambio de rol de los agentes situados en contexto es fundamental porque inyecta intencionalidad y reconoce la contingencia de las condiciones que le rodean.

Palabras-clave: Realismo crítico. Enfoque estratégico relacional. Acción y estructura. México. KWNS y SWPR.

\section{Introducción}

El enfoque estratégico-relacional (SRA por sus siglas inglesas) es una poderosa herramienta teórica para el análisis de los procesos de cambio. Hace

I Gracias a Colin Hay, Matthew Watson, Adam Morton, Magnus Ryner por sus valiosas sugerencias y comentarios. Errores y omisiones son de mi entera responsabilidad. Se agradece la asistencia de investigación, revisión y traducción de Alma Nereida Castañón Soriano.

2 Doutor em Estudos Internacionais na Universidade de Birminghan, Reino Unido. Professor do Programa de Estudios Políticos e Internacionales de El Colegio de San Luis, México. E-mail: h.cuadra.montiel@gmail.com. 
que sea posible determinar la naturaleza contingente y abierta de los procesos en los que los agentes estratégicamente situados se relacionan e interactúan con los demás dentro de un contexto estratégico selectivo (JESSOP, 1990; HAY, 1996, 2002). Los procesos de cambio no violentos que nos preocupan están imbuidos de incertidumbre, inquietud y de contingencia experimentada por las acciones, individuales y colectivas, enfrentando y formando ventanas de oportunidad y restricción en sus interacciones.

Si bien originalmente formulado en un contexto eurocéntrico, el potencial explicativo y argumentativo del SRA, ha trascendido fronteras. La literatura especializada realizada por académicos de otras latitudes por un lado, y la operacionalización del enfoque en otras regiones proporcionan fuerte evidencia de su utilización atendiendo los diversos tipos de cambios en la relación entre el estado y el mercado, por el otro (HEIGL, 2011; SANDOVAL BALLESTEROS, 2005; SERVILLO; VAN DEN BROECK, 2012). El presente artículo busca contribuir a potenciar el desarrollo del enfoque estratégico-relacional, trascendiendo su eurocentrismo original.

El argumento desarrollado aquí procede de la siguiente manera: comienza discutiendo las principales características del Estado Mexicano contemporáneo. Las siguientes secciones discuten el realismo crítico, de qué manera informa al SRA filosófica y teóricamente, y lo que la diferencia de la teoría de sistemas. Teniendo en cuenta el carácter social de las interacciones dialécticas, y la necesidad de re-politizar lo que es presentado como imperativos económicos, los cuales sostienen que los giros institucionales no necesariamente garantizan los objetivos establecidos, debido a los procesos de composición abierta de cambio, donde las interacciones de los actores traen intencionalidad, imprevisibilidad e incertidumbre. Se hace hincapié en una discusión teórica sobre el papel y las características del Estado, sobre todo como un proceso de construcción social atento a las prácticas políticas que continuamente se reconfiguran con el fin de asegurar las condiciones para la creación de riqueza y acumulación de capital. Se pone atención en la transición de los tipos ideales propuestos por Bob Jessop, a partir de un Estado Nacional de Bienestar Keynesiano (siglas inglesas KWNS) a un Régimen Post-nacional Schumpeteriano Laboral (abreviado SWPR, misma lengua). Cada una de las características altamente estilizadas de las propuestas son comparadas con el atípico caso mexicano. El objetivo es demostrar que la influencia teórica 
y analítica del SRA no se limita a tipos ideales eurocéntricos. También se pueden obtener ideas de gran alcance y perspectivas en otros contextos, sin caer en puntos de vista funcionalistas. Puesto que la preocupación está en el proceso de cambio, se hace hincapié en la importancia del papel desempeńado por los actores situados para apropiarse de los procesos interna y endógenamente reproduciendo y contrarrestando tendencias en las que juegan. Finalmente, se destaca la importancia de las prácticas comunes de redes a manera de programas estratégicos en los que las interacciones entre los actores dentro del contexto definido son cruciales para orientar los esfuerzos hacia los objetivos pertinentes.

\section{El régimen presidencial mexicano semi-autoritario}

Aunque México es de acuerdo con su Constitución de 1917, una República Federal, este país mestizo es en la práctica, uno con alta concentración de poder y de toma de decisiones, distintivo de su Presidencia. Es también la razón principal para clasificarlo como un sistema político semi-autoritario, dirigido por una antigua élite burocrática y en la actualidad por una élite tecnocrática. El ejercicio del poder del Presidente ha sido fundamental para las reformas y los procesos de cambio estructural y para la trayectoria de evolución puntuada que el Estado Mexicano ha tomado (CUADRAMONTIEL, 2009). Las características específicas del presidencialismo y del antiguo partido hegemónico dominante han jugado papeles decisivos y funciones modelo de importancia histórica fundamental.

En cuanto a la experiencia mestiza mexicana, lo que ocurrió en las postrimerías de la revolución a principios del siglo XX fue que las políticas gubernamentales orientadas al desarrollo socio-político prefirieron desarrollar prácticas políticas corporativistas de control y ofrecer bienestar social básico. A partir de que las preferencias de mercado a principios de 1980 fueron clasificadas como pieza principal de la agenda el papel del Estado se justifica en términos utilitarios con una relativa aunque controvertida estabilidad (CUADRA-MONTIEL, 2008, 2012). En otras palabras, las redes de bienestar imperfectas de seguridad han ido dando paso a las políticas de flexibilidad laboral.

Históricamente, tanto el presidencialismo mexicano y el Partido Revolucionario Institucional (PRI); han ejercido el poder político concentrado 
(LINZ, 1990). ${ }^{3}$ El Presidente ha sido el principal centralizador de la toma de decisiones del país, subordinando y beneficiándose de la debilidad del poder judicial y del Congreso, desde que la Revolución Mexicana llegó a su fin. El principal límite real formal del poder ejercido por el Presidente ha sido la duración del puesto presidencial, ya que se limita a un período de seis años sin posibilidad de reelección.

Desde su creación, el PRI ha tenido una relación simbiótica con el gobierno, especialmente con el Presidente, hasta el ańo 2000 la cual se reforma, aunque en una nueva etapa a partir de 2012. A pesar de sus diferentes encarnaciones, su principal objetivo ha sido siempre la de proporcionar una base nacional de apoyo político para el gobierno, y evitar una oposición política importante, mediante la existencia de un sistema de amenazas y sanciones para los actores atrapados en las diferentes redes corporativistas y burocráticas (HANSEN, 1971; LEVY, 1990; LEVY; BRUHN, 2001). Esta estrategia de compromiso político y de control funcionó notablemente bien durante varios períodos presidenciales. Sin embargo, aunque no tan poderoso como lo fue en la década de 1940, sigue siendo hoy significativo, a pesar de la presencia política desigual en todo el territorio (CUADRA-MONTIEL, 2009).

El corporativismo y el PRI brindaron estabilidad política, mediante el control institucional de sus intereses y la cooptación de los no representados internamente. Concerniente a la separación de poderes, el legislativo y el judicial eran en la práctica subordinados al poder ejecutivo, mientras que el sistema federal estaba en la práctica fuertemente centralizado y los gobernadores de los Estados de manera similar dependían de la Presidencia (CASAR, 2002). Es bajo esta subordinación política y la agenda del partido dominante, que el poder judicial y el legislativo proporcionaban fuentes de legitimación que permitieron el dominio del imperio de la legalidad, al menos como discurso operativo (DOMINGO, 2000).

Relegado a un segundo lugar después de la agenda económica y financiera, los procesos de liberación política y democratización se movieron a un ritmo más lento que las reformas económicas desde principios de 1980 (CUADRAMONTIEL, 2009). Las reformas políticas no han sido tratadas como rigurosos

3 Para una discusión teórica de las fortalezas y debilidades de los sistemas presidenciales y parlamentarios, y su contraste favorecedor para la democracia, ver a Juan Linz (1990, p. 51-69). 
mecanismos de aplicación auto-inducidos. Sin embargo, ha habido algunos cambios importantes que apuntan hacia una mayor autonomía política y de concentración del poder por medio de procesos más graduales y controlados. En particular, la necesidad de controles y contrapesos independientes para limitar el ejercicio arbitrario del poder discrecional presidencial ha animado a recurrir a las instituciones formales (MAYER-SERRA; HERNÁNDEZ, 2002b; WARD; RODRÍGUEZ, 1999; DOMÍNGUEZ; POIRÉ, 1999).

Es importante tener en cuenta una paradoja relevante en el sistema político mexicano. El anterior partido en el poder, entregó la hegemonía de continuidad, aunque no la homogeneidad, por diferentes medios; éstos incluyen la capacidad de acceder y ejercer el poder con éxito de una manera institucionalizada, mientras se muestra la aplicación y la expansión del apoyo político de la población (SERRANO, 1998; MAYER-SERRA; HERNÁNDEZ, 2002a). No son sólo estas estrategias lo suficientemente flexibles como para tolerar y poner límites a un tipo diferente de participación política, sino que también fueron estratégicamente seleccionadas para fomentar la concentración de poder en que se basó el Presidente. Fue precisamente esta concentración de poder que a su vez le permitió al Ejecutivo un amplio margen para la discreción y la maniobra. Frente a ninguna oposición real, ni un sistema eficaz de controles y equilibrios, las iniciativas presidenciales llevaban a menudo a políticas insostenibles e inconsistentes.

La selectividad estratégica semi-autoritaria, no permitió los esfuerzos para democratizar la agenda política de México para prosperar, sino que se pospusieron una y otra vez en nombre de la estabilidad. Como tales prácticas y discursos se asociaron con un historial democrático deficiente, históricamente, la desconfianza y el escepticismo en los resultados de las elecciones siguen siendo altos. Las instituciones formales tales como el Instituto Nacional Electoral (INE), otrora Instituto Federal Electoral, y el Tribunal Federal Electoral, tuvieron su prueba significativa por primera vez en el año 2006. Mientras que su legalidad fue formalmente indiscutible, una serie de inconsistencias, irregularidades y dobles estándares previos y durante las campańas, después de la elección despertaron sospechas de que la victoria por el mínimo porcentaje de 0,5 por ciento del Partido Acción Nacional (PAN), con el candidato Felipe Calderón, no era legítimo sobre la oposición del candidato Andrés Manuel López Obrador. 
Más recientemente, inclusive en tiempos precedentes a las elecciones presidenciales de 2012, el PRI montó un operativo financiero que implicó fraude fiscal y uso indebido de los programas gubernamentales, además del establecimiento de pactos con los poderes fácticos y mediáticos por medio de contratos amańados y financiamiento ilegal, reportado por observadores nacionales e internacionales. El débil desempeño de las instituciones encargadas de delitos electorales ratifican a ojos de la opinión pública el déficit de legitimidad de Peńa Nieto, siguiendo la peor de las tradiciones de la justicia mexicana: colocando en la víctima la carga de la prueba sin atender sus potestades legales para proceder a investigar por sí mismas, los delitos en que incurrió el PRI en el proceso electoral.

En las secciones siguientes se describen las características relevantes filosóficas y teóricas del realismo crítico y el SRA. En la segunda mitad del artículo es contrastada la experiencia mexicana, sobre la base de esta primera sección, con los tipos ideales KWNS y SWPR.

\section{El potencial del realismo crítico y la teoría para las ciencias sociales}

La ontología realista sostiene que existen diferencias reales entre las experiencias, los acontecimientos y los poderes causales que los generan. Se toma al mundo como independiente de los observadores, y argumenta que las estructuras sociales son las causas materiales fundamentalmente relacional y cardinal de la acción social. La profundidad de la posición realista ontológica conduce su epistemología para centrarse en los poderes causales que subyacen a los patrones y tendencias de los acontecimientos en lugar de las pautas de los acontecimientos como por ejemplo, en el positivismo. A partir de la observación de los patrones de frecuencia diferentes y contrastantes, el realismo propone modelos y mecanismos para explicar los fenómenos observados (BLAIKIE, 1993; LAWSON, 1997, 2003).

El realismo crítico se refiere a una posición filosófica que reconoce la existencia de una realidad objetiva cognoscible que es ontológicamente anterior a la actividad humana actual, a pesar de reconocer los papeles relevantes de la percepción y la cognición. El realismo crítico se asocia principalmente con el trabajo de Roy Bhaskar y las contribuciones posteriores, que su obra ha influido e inspirado. 
Históricamente, es una combinación de realismo trascendental y naturalismo crítico. Bhaskar desarrolló originalmente el realismo trascendental como una filosofía general de la ciencia, seguido por el naturalismo crítico como una filosofía que abarca también las ciencias humanas (ARCHER et al., 1998). Ambos demuestran, entre otras cosas, que los criterios de Hume no son suficientes, ni siquiera es necesario para la atribución de una ley causal. Su trabajo posterior se desarrolla en el realismo crítico para incorporar una teoría explicativa de la crítica y el tema de la dialéctica (BHASKAR, 1987, 1989, 1993, 1994, 1997, 1998). ${ }^{4}$

Para el realismo trascendental, los experimentos científicos tienen lugar cuando los mecanismos reales, manipulables, internos se activan para producir determinados resultados. Esta reorientación de la filosofía se mueve hacia una concepción no antropomórfica del lugar de los seres humanos en la naturaleza. Esto supone un cambio de filosofía en contra de los supuestos del desarrollo monista de la ciencia y el carácter deductivo de la estructura de la ciencia. Una consecuencia de esto es que la ciencia es considerada como un proceso continuo de producción. Si la investigación científica ha de ser fructífera, tanto los científicos deben desarrollar y mejorar los conceptos como implementar, descubrir y analizar los mecanismos cada vez más profundos (BHASKAR, 1975, 1997; ARCHER et al., 1998). Tomando como punto de partida el requisito previo de la identificación de una serie de fenómenos para la construcción de las explicaciones y las pruebas empíricas, se prepara el escenario para el siguiente paso, que puede conducir a la identificación de importantes mecanismos generativos en el trabajo. A medida que estos mecanismos causales se convierten entonces en los fenómenos a ser analizados, la ronda de la investigación científica continúa, de forma recursiva.

Centrándose en las tendencias subyacentes de los mecanismos generativos, el realismo trascendental se ocupa de las cuestiones clave de la intransitividad, transfactualidad y estratificación. Al destacar la concepción relacional de la materia de ciencias sociales, la intransitividad de las entidades aborda la falacia epistémica, que confunde lo que el mundo es con lo que podemos saber sobre él.

4 Los trabajos principales de Roy Bhaskar incluyen Scientific realism and human emancipation (1987); Reclaiming reality: a critical introduction to contemporary philosophy (1989): Dialectic: the pulse of freedom (1993); Plato, etc: the problems of philosophy and their resolution (1994); A realist theory of science (1997); The possibility of naturalism: a philosophical critique of the contemporary human sciences (1998). 
La relatividad de nuestro conocimiento se refiere a la dimensión transitiva o epistemológica, mientras que la dimensión intransitiva u ontológica denota la independencia existencial y/o causal de la realidad del conocimiento humano. En segundo lugar, el concepto de la transfactualidad de mecanismos reconoce que las leyes funcionan independientemente tanto de las condiciones para su identificación y de su identificación en la realidad. Se hace una distinción entre la esfera de lo real y el reino de lo existente. En tercer lugar, la estratificación es intrínseca a todo el mundo, y así se refleja necesariamente en la ciencia (BHASKAR, 1975, 1997; ARCHER et al., 1998).

Al tomar el realismo trascendental como punto de partida, el naturalismo crítico afirma ser capaz de combinar y conciliar el realismo ontológico, relativismo epistemológico y la racionalidad crítica. Se necesita una postura en contra de la filosofía de la ciencia que está dominada por las dicotomías y dualismos. El realismo crítico argumenta que tanto el mundo físico y el humano pueden ser explorados por un modelo realista trascendental de la ciencia. Sin embargo, debido a la imposibilidad de experimentos cerrados en el mundo humano que no pueden garantizar un control completo y total de las variables independientes, la exploración e identificación de los mecanismos sociales deben tener en cuenta los juegos de roles vitales humanos de la acción. Porque es la acción humana dentro de las estructuras sociales la que es capaz de reflexionar sobre la manera consciente, y el cambio de las condiciones que los producen (BHASKAR, 1979, 1998; ARCHER et al., 1998).

La teoría de Bhaskar de la crítica explicativa en sí es una poderosa crítica y refutación del pensamiento filosófico ortodoxo. Al dirigirse a la ley de Hume, que sostiene que la transición de las evidencias a las aseveraciones normativas es inadmisible, reconoce que no es parte del escrito de las ciencias sociales para referirse a los objetos sin valor social. Puesto que las creencias son parte de esos objetos y las ciencias sociales tienen el mandato de criticar las creencias, por lo tanto, tienen la capacidad de emitir juicios de valor y acción. Como las ideas y lo que se acerca puede ser incorporado, representan un campo muy rico de estudio de las ciencias sociales. Lo más importante, se hace evidente que la ciencia explicativa no es neutral. Por lo tanto, la emancipación humana puede ser impulsada por las críticas teóricamente explicativas, como la emancipación en sí depende de la transformación de las estructuras (BHASKAR, 1987; ARCHER et al., 1998). 
El realismo crítico dialéctico tiene como objetivo proporcionar las bases para una nueva teoría ética que se basa en la crítica explicativa. La refutación de la ley de Hume reconoce el carácter de valor implicacional de las ciencias sociales. Entones, la siguiente transición del hecho a valorar es la extensión lógica de la transición de la forma al contenido (BHASKAR, 1993; ARCHER et al., 1998). Tomando "ausencia" como un concepto central, el realismo crítico dialéctico se articula en un proceso - la cadena ontológica-axiológica - que utiliza dialécticamente (en varios pasos) el realismo crítico. El primer momento de la no-identidad transita hacia el segundo borde dialéctico de la negatividad y se enfila a la ausencia de un tercer nivel de las nociones de la totalidad y de la causalidad global orientándose a una cuarta dimensión de la praxis de transformación o de la acción (BHASKAR, 1993; ARCHER et al., 1998). Dado que las relaciones de poder juegan un papel fundamental, el compromiso con la comprensión de la verdad de la situación humana estimuló el objetivo de la autonomía universal humana, que está sin duda implícita en todo juicio moral y en la praxis humana.

A raíz de la hipótesis de Adam Smith de que los seres humanos tienen una propensión "para el trueque, el comercio, e intercambiar una cosa por otra", la ciencia de la economía en su forma neoclásica se convirtió en el estudio del "auto-ajuste" y la "autorregulación" del mercado, atendiendo mecanismos supuestamente desvinculados de todas las relaciones sociales. De este modo se ignora el hecho de que el sistema económico está constituido no sólo por motivos exclusivamente económicos, sino que considera, incorpora y atiende otros fenómenos sociales.

El reduccionista y determinista argumento neoclásico de que las organizaciones, ya sea individuales o colectivas, como los estados y corporaciones, son incapaces de resistir, o incluso de influir, en los dictados de fuerzas económicas impersonales, por lo tanto, son engańosas. Se afirma aquí que los mercados están integrados en grandes sistemas sociales y políticos, donde los diferentes actores e instituciones interactúan unos con otros y promueven sus propias agendas. No es de extrańar que los gobiernos nacionales se encuentran entre los actores más importantes e influyentes, no sólo en el ámbito económico, sino también - como se verá más adelante - en los más amplios sistemas sociales y políticos, porque los mercados son inherentemente políticos. Por lo tanto, como lugar de la interacción humana, los mercados 
son una parte constitutiva de un más amplio y complejo, dinámico y siempre cambiante conjunto, donde la realidad social no puede y no debe reducirse exclusivamente a los ámbitos de la oferta y la demanda.

Este artículo reivindica el campo de estudio de la economía política como ciencia social. Se reconoce que al sostener tácitamente conceptos de tradición y linaje positivistas la argumentación teórica pierde la riqueza de la interrelación entre las esferas social, política y económica. El realismo crítico por su parte al ser una filosofía de y para las ciencias sociales, favorece la fertilización cruzada de enfoques y posiciones no solo transdiciplinarias y multidisciplinarias, sino el carácter mestizo, forjado en el crisol de las ciencias sociales. De las diversas posiciones filosóficas de la ciencia en general, es en el universo de las ciencias sociales donde se favorecen los mestizajes de ideas y realidades, las mezclas del ser y el deber ser, y los maridajes de conceptos y preceptos que el puritanismo naturalista prescribe y condena. El realismo crítico es y debe ser mestizo debido a su acertada fundición en el crisol de la realidad y la emancipación. En resúmen, el realismo crítico es social, es político, y es mestizo. Permite que el estudio y la praxis de las ciencias sociales sea cada vez más propio, mas cercano a su realidad y más adecuado para su transformación. El mestizaje de su carácter emergente es a su vez condición dialéctica que permite ulteriores procesos de cambio y liberación.

Después de haber sido precisadas las principales características filosóficas del realismo crítico, es la tarea de la siguiente sección desarrollar un enfoque adecuado a la complejidad firmemente arraigado en la posición filosófica de este último.

\section{Realismo crítico, enfoque estratégico-relacional y la teoría de sistemas}

Basándose en el naturalismo crítico de Bhaskar, el enfoque estratégicorelacional (SRA por sus siglas inglesas) reconoce el papel central de la sociedad no sólo como condición, sino también como resultado de la acción humana, tal como se especifica en el modelo de transformación de la actividad social. Huelga decir que esta no es una característica estática, como las acciones individuales y de grupo, ambas reproducen y cambian la sociedad simultáneamente. En el contexto de un mundo social pre-estructurado, las 
percepciones falibles y limitadas de los actores de lo que están haciendo en sus actividades constituyen el punto de partida de la investigación social. ${ }^{5}$

Se trata de la intencionalidad de la acción humana que contribuye con un rasgo distintivo del modelo de transformación de la actividad social. Debido al hecho de que la sociedad no sólo es la causa material siempre presente y a que el resultado se reproduce continuamente de la acción humana, la sociedad presenta dualidad de la estructura y dualidad de la praxis (BHASKAR, 1979, 1998). La reproducción y transformación de la sociedad y los individuos se produce a través de la mediación relacional de las posiciones y prácticas. Por lo tanto, el atomismo social y el individualismo metodológico chocan con el potencial emancipador de las ciencias sociales. Además de los hechos, las competencias, las acciones y las oportunidades en que las teorías científicas sociales se basan, las circunstancias dentro del cual se ponen los conocimientos que se obtienen y la intencionalidad de los actores contribuyen a crear sus propias oportunidades para ampliar aún más la ciencia (BHASKAR, 1987).

Cruciales como las posiciones filosóficas críticas realistas son para el SRA, hay otras fuentes teóricas que aportan las herramientas de investigación para su arsenal. Por ejemplo, considérese el debate de estructura y acción social, donde a pesar de la crítica realista sobre la presentación Giddensiana, se reconoce más en términos de aleación de metales, que de las caras de la moneda (HAY, 1995). Por otro lado, Luhmann representa una innegable influencia. Para este último autor, los sistemas son auto-referenciales y auto-reproductivos, aún así no pueden existir fuera, y deben diferenciarse de su entorno (LUHMANN, 1998). A pesar de que la idea de autopoiesis no está totalmente desarrollada, la auto-referencialidad de una manera relacional es una característica y punto de partida importante para el SRA.

Lo más importante es que el realismo crítico mestizo y la teoría de sistemas comparten una definición similar de lo que las características de una teoría deben ser. Tampoco adoptan una definición estructural. Ambos evitan

5 Según Bhaskar (1998), explicaciones teóricas y explicaciones aplicadas difieren en aspectos fundamentales. Las explicaciones teóricas proceden de la descripción de las características significativas, retroducción de las posibles causas, la eliminación de alternativas, y la identificación de los mecanismos generativos o estructuras causales en el trabajo. Por otro lado, las explicaciones se aplican a seguir un procedimiento diferente por la resolución de un caso complejo en sus componentes, redescripción teórica de estos componentes, retrodicción a posibles antecedentes del componente y la eliminación de otras causas. 
las explicaciones deterministas y no promueven o participan en la definición $\mathrm{u}$ orientación de modelos matemáticos. Dejando a un lado orientaciones parciales, tanto el realismo crítico y la teoría de los sistemas siguen una estrategia similar a la 'cartografía', debido a que mantienen sus características específicas, el énfasis y las preferencias en los mapas que les ayudan a identificar los principales puntos de partida en la investigación (LUHMANN, 1996, 1998). Además, este procedimiento ayuda a mostrar la evidencia de las relaciones que han de ser resaltadas. Importante como es el énfasis relacional, es evidente en el uso que hagan de los conceptos, que están en relación compleja uno a otro. La complejidad, la indeterminación y la contingencia de los sistemas dependen de las capacidades relacionales de los actores.

A pesar de estas similitudes relevantes, existen diferencias cruciales entre la teoría de sistemas y el realismo crítico mestizo. Luhmann, en concreto hace hincapié en la comunicación como la esfera relacional fundamental, ya que sostiene que toda comunicación es, en y dentro de la sociedad. Como la sociedad se comunica acerca de sí misma y su entorno, no hay un reconocimiento del papel transformador de los agentes del juego, cuando argumenta que no es la gente, sino la comunicación lo fundamental. Luhmann sostiene que a medida que los sistemas sociales están constituidos por acciones, es por sus propias acciones que los individuos entran en el sistema. Por otra parte, según él, los sistemas sociales implican los procesos de comunicación que son diferentes de las acciones propias, donde el lenguaje funciona como un medio de selectividad coordinada.

Lo más importante es destacar que los planteamientos teóricos del SRA se construyen sobre la base filosófica del realismo crítico mestizo enfatizando un carácter relacional, en lugar de la comunicación. La falta de un concepto que identifique la intencionalidad de la acción por parte de los actores sociales a manera de funcionamiento que puede no alcanzar su objetivo, es una diferencia importante entre el SRA y la Teoría de los Sistemas. Esta falta es un rasgo distintivo de la última teoría, aunque puede haber variantes, tales como la progresiva "des-antropomorfización" de la ciencia propuesta por Ludwig von Bertalanffy. Su posición defiende explícitamente la eliminación de toda experiencia humana y de emprender, más bien, la caza del conocimiento absoluto a través de sistemas de las relaciones matemáticas (BERTALANFFY, 1986). Es evidente que esto no es una posición compartida tanto por los 
realistas críticos o por el SRA. Por lo tanto, la cuestión clave aquí es la recuperación de la acción de los individuos, como no sometida a fuerzas y procesos anónimos.

Con respecto al SRA, de forma explícita Jessop plantea el realismo trascendental como su posición ontológica y un realismo crítico en dos etapas, como su epistemología (JESSOP, 1990). Debido a la naturaleza altamente compleja de las características de los fenómenos seleccionados para el análisis, es altamente improbable que se deban a una variable independiente o a un solo mecanismo generador. En cambio, la probabilidad de la interacción y la interrelación entre las diversas tendencias no homogéneas causales y contratendencias indican sistemas abiertos a la contingencia en lugar de sistemas cerrados totalmente controlados para la experimentación. Inclusive se ha propuesto la construcción social de sistemas de planeación considerando el enfoque estratégico relacional (SERVILLO; VAN DEN BROECK, 2012). Estas características de sistemas abiertos son, sin duda, útiles para acercarse a procesos abiertos de cambio y el Estado como una relación social, como se verá más claro en las siguientes secciones.

\section{Acercarse a procesos sociales de cambio y al estado}

Se han hecho intentos para realizar estudios comparativos e históricos de los diferentes Estados en diferentes continentes. Por otra parte, el enfoque del Estado como una configuración de organizaciones se ha orientado hacia la visión como un conjunto de instituciones que enfatizan el control social, con autoridad para tomar decisiones y la implementación de políticas (GRINDLE, 1996). El problema es que, sin reconocer el carácter socialmente integrado de las interacciones que continuamente conforman los procesos de cambio, no deja espacio para el análisis de la incertidumbre y la imprevisibilidad asociada con la dinámica de la apertura de los sistemas sociales. Otra dificultad con las perspectivas de análisis de este tipo es que tienden a tratar a las instituciones como si fueran permanentes, otorgando primacía a los puntos de vista estructural y determinista y la preocupación por la gestión de las políticas macroeconómicas (GIUGALE; LAFOURCADE; NGUYEN, 2001; GRINDLE, 1996).

El papel central que desempeńa el Estado en los asuntos económicos y políticos es crucial para el argumento que aquí se presenta. Tomando en consideración la herencia del pensamiento clásico weberiano, no sorprende 
que la forma más fructífera de analizar la permanente interacción del Estado con las transformaciones sociales y económicas, es a partir de la síntesis de las esferas supuestamente separadas de la política y la economía (SANDOVAL BALLESTEROS, 2005). Dar prioridad a un énfasis estrecho de la reestructuración económica sin tener en cuenta las políticas redistributivas adecuadas ha contribuido a acentuar los patrones de desigualdad en todo el mundo (VREELAND, 2003). Entre las economías de América Latina, la brecha de México entre los más ricos y los peor situados, mantiene un inquietante crecimiento. La suposición de que, una vez que el marco institucional está en su lugar, la población puede encontrar la manera de prosperar cuando las autoridades abren nuevas oportunidades de negocio, no se ha materializado para una gran parte de la población en ese país. Tanto el mercado y el gobierno son propensos a fallas, dado que la información imperfecta, mercados incompletos, la ineficiencia y la interrupción afectan a ambos. El sector público y privado siguen lógicas opuestas. Los objetivos económicos y no económicos son cruciales para el primero, mientras que la búsqueda de ganancias representa el objetivo principal de este último. Reconociendo que los mercados no son ni "auto-regulables" ni "auto-ajustables" ponen de manifiesto el papel que debe jugar la intervención del gobierno, especialmente con fines de redistribución (STIGLITZ, 1989, 1994, 1998b).

La expansión de la protección social de los mercados, como Polanyi sugirió, representa un componente esencial de la dinámica social que no acompaña a la expansión del mercado sincrónicamente (POLANYI, 1957). Hay una clara necesidad de que el gobierno desempeñe un papel activo en la aplicación de políticas redistributivas y de asistencia, lo que, a su vez, mejorará la asignación de un mercado más eficiente de los recursos. No tomar en cuenta este hecho aumenta el riesgo principal de salir de los mercados para asignar recursos por su cuenta, aumentando la concentración de la riqueza en pocas manos, mientras que se ampliará la brecha entre los ricos y los sectores desfavorecidos de la sociedad. Tal polarización económica es una falla de mercado que deja a los gobiernos la tarea vital de las necesidades sociales, la entrega de asistencia social, la provisión de bienes y servicios adecuados y facilitar la competencia (CUADRA-MONTIEL, 2007, 2011). Estas últimas cuestiones no son de ninguna manera incompatibles con las capacidades de cualquier gobierno, ya que los niveles crecientes de competencia en el mercado son, a su vez, las 
disposiciones contra los fallos públicos, como el aumento de los incentivos ayuda a atenuarlas (STIGLITZ, 1991, 1998a, 2002).

\section{Un enfoque realista crítico para el estado}

El Estado es uno de los grandes temas y objetos de estudio en ciencias políticas y disciplinas afines. Célebremente aproximarse al control político y hacer hincapié en los medios de coerción sobre una población confinada dentro de ciertos límites territoriales, se han ganado un estatus de clásico en el amplio espectro de las ciencias sociales en general (WEBER, 1979). Dado que los exponentes del SRA han seguido una revisión sistemática de la literatura especializada y el análisis teórico del Estado, la presente investigación destaca contribuciones de dicho enfoque en esta sección. En Re-Stating social and political change, Colin Hay presenta una breve reseña crítica de la literatura, además de un análisis de Gran Bretańa desde la segunda post-guerra mundial. Jessop ha escrito, The capitalist state, State theory, The future of the capitalist state y State power (JESSOP, 1982, 1990, 2002, 2008). ${ }^{6}$ Mientras que el segundo no sólo analiza una amplia gama de diferentes fuentes sobre el Estado en el momento mismo que hace una contribución seminal, el tercero, avanza el debate por ir más allá de su posición original y presenta teóricamente tipos ideales informados.

Es en la obra State power: a strategic-relational approach que dentro de la primera parte que teoriza sobre el Estado se encuentra una sección que identifica tres abrevaderos y raíces teóricas del SRA, además de la distinción de tres diferentes fases sobre las que ha transitado la construcción teórica del enfoque, advirtiendo que es todavía una obra inconclusa. En la segunda parte se hacen muy explícitas las contribuiciones que las obras de Marx, Gramsci, Poulantzas y Foucault han significado para el enfoque. La tercera sección amplia los ámbitos de aplicación del SRA. State power es sin duda, la presentación más lograda del enfoque estratégico relacional y el estudio del Estado (JESSOP, 2008).

Es evidente que, si a la prestación de bases institucionales para el mercado se da prioridad a lo largo de más inclusión social, la agenda política del Estado,

6 Además de un gran número de artículos especializados y capítulos de libros 
es más que favorable al mercado, trascendiendo el rol de "socio, catalizador y facilitador" de las actividades económicas (WORLD BANK, 1997). Porque, yendo más allá de una posición estructural y determinista influenciada por la economía neoclásica y el positivismo, obliga a la acción de los actores a tener en cuenta el papel que desempeñan en la construcción de los procesos de cambio.

Dado que el Estado también es parte de un contexto social, debe ser visto desde una perspectiva más amplia. A pesar de que podría ser considerado de forma aislada con fines analíticos, las relaciones sociales dinámicas y complejas que continuamente se reforman lo convierten en un sitio, generador y producto de estrategias. En la formación de los patrones de dependencia, estas estrategias para la toma de decisiones futuras se basan en el pasado, y en este sentido están a favor de algunas de las estrategias sobre las demás, donde el despliegue de las características específicas de selectividad estratégica nunca son neutrales (JESSOP, 1990).

Para el SRA, el Estado es

[...] un conjunto de instituciones socialmente integrado, socialmente regularizadas y estratégicamente selectivas, organizaciones, fuerzas sociales, y actividades organizadas en torno a (o por lo menos participan activamente en) la toma de decisiones colectivamente vinculantes para una comunidad política imaginada (JESSOP, 2002, p. 6 y 40).

Es de tal fluido y evolución el sistema, donde la serie de prácticas y procesos dinámicos y complejamente entretejidos cuentan con características condicionales y relacionales, que el ejercicio del poder lleva a cabo.

Los procesos interminables y siempre auto-renovados de formación del Estado y de reconfiguración, se deben al carácter relacional del poder ejercido por los actores situados estratégicamente en contextos selectivos, constituyendo lo que se percibe como el poder del Estado. Dado que las sociedades no pueden estar organizadas y coordinadas desde un centro único, ya que el poder nunca es externo a las relaciones sociales, se ha argumentado que el Estado no tiene poder propio. Más bien, es el ejercicio continuo de interacciones, el cual construye una relación social compleja que refleja los cambios de fuerzas en combinaciones específicas. ${ }^{7}$ Por otra parte, el conjunto

7 De acuerdo con Jessop, el poder se refuerza a través de la movilización de apoyo a las políticas y a través de la monopolización de los medios de coerción. Ver Jessop (1990). 
de instituciones media las relaciones reflejadas del equilibrio de fuerzas sociales generales y de los aparatos estatales específicos (JESSOP, 2002). Además, la apertura, mantenimiento y restauración de las condiciones para la creación de riqueza y acumulación de capital, sin duda, son características vitales del Estado (JESSOP, 1990, 2002).

Es precisamente la preocupación de asegurar estas condiciones que orienta las principales funciones del Estado. Tal énfasis en los objetivos de la acumulación sobre los objetivos de legitimación hace caso omiso de cualquier preocupación por la equidad. Esto se hace más evidente cuando las prácticas que tienen como propósito garantizar que se aproveche la mercantilización ficticia de la tierra, trabajo, dinero y conocimientos. El carácter socialmente integrado de las actividades económicas, exige el reconocimiento de los límites contenciosos trazados por la economía neoclásica. Por otra parte, es importante la promoción de condiciones adecuadas para la producción, distribución e intercambio de bienes y servicios, pero también se debe prestar atención a cuestiones tales como la articulación de los procesos relacionados entre sí, el orden jurídico y los derechos de propiedad. Es necesario ser consciente de todas estas funciones generales del Estado en relación con el mercado, si queremos abordar con éxito las repercusiones sociales y políticas de favorecer las condiciones generales y particulares para actividades con ánimo de lucro y mediadas por el mercado (JESSOP, 2002).

Dado que el Estado es un "fenómeno polivalente y policontextual", la forma y las apariencias que asume pueden ser narradas y trazadas como procesos sociales, además de utilizarse como referente para dar seguimiento a los procesos de cambio. Es importante reconocer que, a pesar de que las guerras y los conflictos militares son factores externos importantes en los cambios, el enfoque está orientado a los procesos pacíficos que tienden a seguir patrones de evolución. Los procesos de cambio social deben ser apropiados internamente y digeridos por las organizaciones. Tanto la participación individual y colectiva, y la propiedad son necesarias si se quiere que sean parte de la dinámica de los sistemas abiertos. Desde el ámbito del Estado y su forma de cambio a través de la historia, los patrones de evolución específicos tienen algo que decirnos acerca de las características generales del cambio social (HAY, 1996).

Los patrones continuos de cambio y la continuidad de los procesos sociales muestran tendencias y contratendencias al mismo tiempo. Por ejemplo, tres 
tendencias se han identificado en relación con la reestructuración del Estado. Se trata de la desnacionalización del Estado, la des-estatización de la política y la internacionalización de los regímenes de política (JESSOP, 2002). Estas tendencias, a su vez, en coincidencia con contratendencias, incluyen un mayor alcance en la articulación y la primacía de las escalas espaciales, además a nivel nacional, existe un papel ampliado de "meta-gobernanza" y la impugnación de las formas, y la aplicación de los regímenes internacionales (JESSOP, 2002). Por lo tanto, no debería ser una sorpresa que el Estado sea un actor central y algunas veces un árbitro en una amplia variedad de regímenes. En pocas palabras, "no debería ser sólo un objeto, sino también un agente de la regulación” (JESSOP, 1990, p. 315).

Para los teóricos de la regulación, algunas de las prácticas fordistas y postfordistas, las estrategias y los vínculos, se han extendido de forma selectiva. Desde la década de 1960, algunas de las economías más desarrolladas, a fin de superar una desaceleración de la productividad, han trasladado algunas de sus actividades industriales y de manufactura al extranjero, principalmente hacia América Latina y el Sudeste Asiático. El problema es que ha sido una articulación parcial y segmentada con restricciones tecnológicas. Como resultado de ello, no ha emitido un círculo virtuoso endógeno, sino que ha aumentado la dependencia externa y la subordinación a las principales economías. Además de los problemas de la desigual distribución del ingreso y las prácticas no sustentables, la imposibilidad de ampliar y desarrollar los mercados nacionales de forma endógena tiene consecuencias preocupantes que no pueden ser ignoradas. Debido a los vínculos con los mercados externos que tienden a truncar la articulación de los mercados nacionales, los patrones de exclusión social en el "fordismo periférico" se han convertido en un problema importante (PECK; TICKELL, 1994; DUSSEL PETERS, 1997, 2000; FAJNZYLBER, 1990). En las secciones siguientes se describen dos tipos ideales de transición introducidos por Jessop. Este ejercicio teórico nos permite examinar características mestizas no coincidentes de la experiencia mexicana como una referencia no eurocéntrica y contribuye no sólo a ampliar la literatura en espańol del enfoque estratégico relacional (SANDOVAL BALLESTEROS, 2005), sino que ha propuesto operacionalizar al SRA en ese contexto (HEIGL, 2011). 


\section{La transición del KWNS al SWPR}

El hacer hincapié, en la medida de la evolución de los procesos sociales, es un notable ejercicio teórico desarrollado por Jessop de dos tipos ideales muy estilizados. Una cuestión fundamental a tener en cuenta es que su propuesta se centra en los tipos que podrían estar asociados, aunque de manera imperfecta, con un conjunto de economías avanzadas, en particular las anglosajonas y las del norte de Europa. Él restó importancia a la consideración de diferentes experiencias nacionales. Argumentando que las principales características y la dinámica del Estado como los procesos sociales no se han desgastado, y que las funciones del Estado se realizan, aunque modificadas, no han sufrido un retroceso general, se involucró en estilizar los tipos imaginados. Manteniendo los elementos fundamentales del Estado en su lugar, los cambios que se observan corresponden a las características de los tipos ideales (JESSOP, 2000, 2002).

Jessop, argumenta que el tipo ideal del Estado Nacional de Bienestar Keynesiano (KWNS) ha sido parcialmente erosionado y tendencialmente reemplazado por uno de un tipo diferente, a saber, por el Régimen Postnacional Schumpeteriano Laboral (SWPR). Se procede a explicar brevemente los perfiles de estos tipos ideales. Ambos destacan la subordinación de las políticas sociales a las políticas económicas. Al mismo tiempo, hacen hincapié en la primacía de la escala territorial o geográfica a la que trabajan, y los medios utilizados para compensar las fallas del mercado.

En primer lugar para el tipo ideal del KWNS, la etiqueta "keynesiana" proviene de la provisión de la infraestructura para proporcionar los medios para la producción masiva y consumo masivo de bienes y servicios, mientras que el objetivo es máximo empleo y gestión de la demanda. Este conjunto de políticas económicas se presenta como un apoyo a la expansión de los derechos de asistencia social, principalmente a nivel nacional. Además, el Estado se enfrenta a la tarea de compensar las fallas del mercado (JESSOP, 2000, 2002).

Para el segundo tipo ideal, el SWPR, la etiqueta "schumpeteriana" proviene de la meta de lograr un mayor grado de innovación, principalmente técnica y de competitividad económica que ayude a ampliar la utilización y difusión de las tecnologías de comunicación e información en la llamada economía basada en el conocimiento. Tales preocupaciones se asientan sobre la demanda de las economías abiertas. Además, la subordinación de las políticas 
sociales a las políticas económicas es más fuerte en este tipo, los derechos sociales son atacados y hay una presión a la baja del "salario social", que hace hincapié en el carácter de prestaciones sociales condicionadas de la política social. Por otra parte, la etiqueta de post-nacional se utiliza para denotar el aumento en la importancia de algunas otras escalas geográficas y espaciales en relación con la nacional (aunque sigue siendo fundamental). Del mismo modo, la creciente importancia de las redes para la compensación por fallas del mercado se presenta como el surgimiento de regímenes donde el Estado interviene en las cuestiones de "meta-gobernanza".

Una transición de los términos estilizados típico-ideales del KWNS al SWPR se dice que ocurre, teniendo en cuenta la acumulación de capital y la creación de riqueza a través de la mediación de las relaciones sociales del mercado y extra mercado. Esta transición incompleta e imperfecta se lleva a cabo al mismo tiempo, donde las condiciones que reproducen y mantienen la mercantilización ficticia de la tierra, el dinero, el conocimiento y el trabajo se mantienen en su lugar (JESSOP, 2002).

Un conjunto de casos se pueden asociar con el primer tipo ideal. Asimismo, un número muy pequeńo coincide con las características del segundo. Ni que decir, ninguna de todas las características del KWNS, ni las del SWPR, podrían estar asociadas con los procesos sociales de cambio y con la mercantilización que nos ocupa en este artículo. Ni la región de América Latina en su conjunto, ni el caso mexicano en concreto, corresponden a ningún tipo ideal estilizado. Sin embargo, se pueden poner a buen uso al alejarse de todo el conjunto de características ideales y su presentación completa de la imagen, hacia una imagen particular más nítida y más clara, individual y desagregada.

La rigidez funcionalista y la falta de flexibilidad que aparece a primera vista, tanto en el KWNS y en el SWPR podrían reducirse drásticamente si cada una de las características de los tipos ideales fueran consideradas como sustantivos en lugar de adjetivos. Es decir, mi objetivo es tomar cada una de las características, sin ponerlas en cualquier camisa de fuerza que podría reducir los matices de los sujetos y los objetos bajo escrutinio. Más importante aún, la falta de opciones que la transición de un tipo ideal a otro parece transmitir,

8 El termino meta-gobernanza fue originalmente sugerido por Hay. 
podría ser superada mediante la revitalización de la función de agencia desempeñada por una organización. Esta medida nos permite eliminar las restricciones y rigideces, a la vez que el espectro de opciones disponibles y viables para las organizaciones se amplía significativamente.

\section{Más allá de una combinación ideal}

Se toman en cuenta no sólo las transformaciones materiales de los contextos, así como también los factores ideacionales que se entretejen en los procesos sociales, políticos y económicos del cambio en el México contemporáneo. En concreto, son particularizadas las ocho características sugeridas por Jessop, de los dos tipos, verificándolos con la evolución puntual de los procesos mexicanos. A primera vista, esto puede parecer una elección extraña, considerando que ni la concepción del KWNS ni del SWPR se formularon con México en mente. ${ }^{9}$ Por el contrario, las características altamente estilizadas de ambos tipos ideales acentúan aspectos distintivos a los que un número muy pequeño de casos, sobre todo anglosajones y del norte de Europa, han realizado la transición. A pesar de que no describen la realidad concreta, proporcionan un punto de referencia indiscutible en consonancia teórica e ideal, que sirve para evaluar la condición misma de la acción, que es la capacidad para formular estrategias. Como tal, podrían ser de gran ayuda para imaginar más y cristalizar las rutas alternativas y cursos de acción que estén abiertos para los responsables líderes y gobernantes en México. Esto es así porque el valor de la teoría y los tipos ideales son, entre otras cosas, para informar y enriquecer el debate, no para cerrarlo, ya que las ideas tienen un impacto mixto causal y constitutivo sobre el mundo material y los resultados ideacionales (WATSON, 2000; HAY, 2002).

Primero que nada, con respecto a los conjuntos de las políticas económicas y las ideas, no puedo catalogar la experiencia mexicana como típicamente keynesiana. Las políticas económicas y las estrategias que se implementaron originalmente en el México posrevolucionario precedieron a la difusión de

9 Cuando se habla de las diferentes variantes del KWNS y algunos de los problemas del Tratado de Libre Comercio de Norteamérica, hay una referencia muy breve a México como un país afectado por la dominación del capital de los Estados Unidos. Ver Jessop (2002). Del mismo modo, en cuanto a teoría de la regulación, la experiencia mexicana es considerada como una variante periférica del fordismo, donde su principal caracteristica es que algunos productos de exportación son ensamblados localmente. Ver Peck y Tickell (1994). 
las ideas de Keynes, y más aún precedieron a la de la Comisión Económica para América Latina y el Caribe de las Naciones Unidas (CEPAL). ${ }^{10}$ Décadas más tarde, este tipo de estrategias y experiencias nacionales informaron la mencionada construcción teórica (CALVA, 2000). Con respecto a lo anterior, el máximo empleo, la piedra angular de las políticas keynesianas nunca estuvo al alcance. No estaba completa la demanda de implementar la gestión, y no se hicieron los esfuerzos para entregar la infraestructura y llegar a un estado óptimo en la historia económica del país. Sin embargo, es imposible negar la influencia de Keynes, y la importancia de sus ideas, las que se hicieron sentir en los círculos gubernamentales y académicos, especialmente durante los años 1950s y 1960s (BABB, 2001). Había una coincidencia con las estrategias de desarrollo estabilizador mexicano y con su pensamiento que contiene consejos sobre la industrialización de sustitución de importaciones. Por ejemplo, la idea de Keynes que el Estado tiene un papel que desempeñar en la orientación de la propensión a consumir y en el incentivo para invertir. Del mismo modo, hubo un grado progresivo de socialización de la inversión, donde el tema clave que guía la política económica no era tanta preocupación por la propiedad de los medios de producción como la entrega de las condiciones adecuadas para las actividades económicas, tanto como Keynes lo había defendido."

Sin embargo, una caracterización Schumpeteriana de México es aún más problemática, sobre todo cuando el término se toma para poner de relieve la innovación, ya que hay una falta preocupante de ella en México en las actividades económicas de manufactura. Por lo tanto, el conjunto distintivo de las políticas económicas de México no coincide con el tipo ideal sugerido por Jessop. Contrario a este énfasis Schumpeteriano, la orientación contemporánea de las políticas económicas del gobierno ha prestado poca atención a la facilidad y promoción de innovadoras combinaciones que podrían ayudar a establecer las bases para una economía basada en el conocimiento. Poca atención se ha prestado a la calidad de la inserción de la industria y los vínculos en México, donde hay una preocupante falta de conexión entre

10 La obra de Keynes fue una influencia sobre los economistas de la CEPAL y los funcionarios gubernamentales por igual.

II En sus propias palabras, "no es la propiedad de los instrumentos de producción, lo que es importante para el Estado asumir. Si el Estado es capaz de determinar el monto total de recursos dedicados a aumentar los instrumentos de producción y la tasa básica de remuneración de quienes los poseen, se ha logrado todo lo que es necesario" (KEYNES, 1964, p. 378). 
los enclaves y conjuntos de actividades económicas (CIMOLI, 2000). Los débiles eslabones endógenos entre las empresas nacionales y entre los sectores económicos orientados a la exportación deben ser reforzados a fin de revitalizar y fortalecer el mercado interno al tiempo que obtienen una mejor posición en el extranjero (DUSSEL PETERS, 1997, 2000). Si el objetivo de la absorción, el desarrollo, la incorporación y la innovación de la tecnología se quiere lograr, sectores y actividades seleccionados deben dirigirse a los beneficiarios de los programas de política industrial (FAJNZYLBER, 1990).

En cuanto a las políticas sociales, México no ha tenido nunca un Estado de bienestar comparable a los de países europeos o anglosajones. Aunque el bienestar básico se proporciona, las redes de seguridad tienden a ser poco fiables e imperfectas, sobre todo para los sectores sociales que más lo necesitan. Sin embargo, la preocupación por la protección social del mercado no ha estado del todo ausente. Lo que México ha tenido son prácticas corporativas para la participación política y el control de los grupos sociales. Éstas proporcionan mejoras iniciales en materia de educación, condiciones sanitarias y de vida en general, aunque principalmente en las zonas urbanas (REYNOLDS, 1970; HANSEN, 1971; LUSTIG, 1998). Las prácticas de desmercantilización han sido subordinadas frente a la preocupación para mantener la estabilidad política, la atracción de la inversión y la amortiguación de las presiones y demandas sociales. Sin embargo, el actual énfasis en la flexibilidad del mercado laboral y la subordinación de la política social a los imperativos económicos de México da prioridad a una estrategia de prestaciones sociales condicionadas que, lamentablemente, está más cerca del tipo ideal Schumpeteriano que la contraparte de bienestar (DUSSEL PETERS, 1997, 2000; CIMOLI, 2000). Para los procesos de mercantilización en México, basta con argumentar que uno de los aspectos más crueles del trabajo se encuentra en las industrias manufactureras, donde, en una gran proporción de los casos, los trabajadores de baja calificación y habilidades, junto con incentivos fiscales adicionales, son tomados como ventajas competitivas (GEREFFI, 1996; GEREFFI; KORZENIEWICZ, 1994; GEREFFI; WYMAN, 1990). Dicha estrategia fundamental es muy problemática, ya que acentúa y refuerza los patrones de desigualdad (CUADRA-MONTIEL, 2012).

A pesar de la primacía relativa de la escala nacional para la ejecución de las políticas sociales y económicas, y los programas que han sufrido modificaciones 
en México, ésto no es lo mismo que decir que ha sido superada por la importancia de otros niveles. Es evidente que, a lo largo de los ańos ha habido cambios, y la aparición de las agendas locales, regionales, internacionales y transnacionales no debe ser ignorada. Sin embargo, la primacía de la escala nacional es, sin duda, fundamental para las cuestiones esenciales. En cuanto a la nación, las variaciones, los debates y los cambios a través de la historia han contribuido a su naturaleza controvertida y metamórfica continuamente. Casi dos siglos de historia independiente, turbulenta, y una tendencia hacia la "unidad impuesta", por una parte, y el desafío de las ideas tradicionales y los patrones de la nación y sus intereses, por el otro, siguen influyendo en las percepciones de los mexicanos (MORRIS, 1999). El nacionalismo no sólo tiene razgos que tienden a asociarse con una identidad nacional, sino también el papel desempeńado por las ideas, discursos e ideologías en la definición de los intereses nacionales, no pueden ser fácilmente separados de los cursos de acción, políticas y estrategias de un tono nacionalista (KRAUZE, 1997). Las interrelaciones entre la identidad, los intereses y las políticas cuentan con arraigo social, y los determinantes que afectan dialécticamente y son afectados por la dinámica del cambio, a través de la promoción de cambios en la identidad, intereses y políticas (MORRIS, 1999).

Algo similar ocurre con el papel del Estado. Dentro de contextos siempre cambiantes y estratégicamente selectivos, el Estado mexicano ha sido, y seguirá siendo, un actor central, aunque sea uno que no siempre actúa de forma coherente. La participación pública y privada en una variedad de diferentes regímenes no necesariamente significa la erosión irreversible del Estado, porque no son juegos de suma cero. Por otra parte, retomando a Stiglitz, se puede decir que tanto el mercado, como el gobierno, poseen una propensión a asimetrías de información e imperfecciones, ineficiencias e interrupciones que afectan a ambos (STIGLITZ, 1989, 1991, 1998b). La auto-organización no es libre de fallos tampoco, y por lo tanto no ofrece ninguna garantía de ningún tipo de compensación. Considerada desde esta perspectiva, y más como opción complementaria, la importancia de los regímenes para hacer frente a fallos del mercado y del gobierno no se debe exagerar.

Como puede verse, México no se ajusta a los tipos estilizados agregados, y ni siquiera coincide con la mayoría de las características individuales sugeridas para los KWNS o para el SWPR. Sin embargo, esto no debe 
disuadirnos de hacer uso del SRA, dado que no debe ser considerado como una debilidad de este enfoque, ya que no lo es. Este es un enfoque que no sólo es capaz de sugerir las tipologías ideales, sino que también nos permite explorar las relaciones causales en una variedad de procesos, tales como la mercantilización (CUADRA-MONTIEL, 2008, 2012). Otros, como la autonomía política y la democratización, también se podrían considerar así (CUADRA-MONTIEL, 2009).

Una contribución notable respecto al uso del enfoque estratégico relacional lo propociona Heigl, con su destacado análisis de la serie de iniciativas encaminadas a facilitar la polémica privatización del sector petrolero mexicano (2005). En este caso no sólo el peso de las ideas neoliberales ha sido suficiente, dado que la fuente de ingresos provenientes de Pemex, que justamente destaca la Secretaría de Hacienda, no ha logrado ser compensada con los ajustes y reforma fiscal propuestos por las mas recientes administraciones del gobierno mexicano.

En resumen, el SRA es una herramienta poderosa y bien equipada para el seguimiento de procesos. Se puede utilizar cualquier proceso, desde un tipo ideal a otro, o para la investigación de momentos históricos específicos y trayectorias. ${ }^{12}$ En este punto, se debe prestar más atención a las estrategias, mecanismos y factores que juegan un papel en la conformación de los procesos sociales de cambio.

\section{Hacer realidad el cambio: participación y apropiación de los actores}

Stiglitz ha argumentado que "la participación y la apropiación" son fundamentales para catalizar el cambio "de toda la sociedad", ya que promueven el objetivo fundamental del desarrollo. Dado que para él este último implica la "transformación de la sociedad", donde el cambio eficaz no se puede imponer desde fuera, la participación activa en los procesos aumenta el grado de propiedad de los actores. Si esto sucede, los actores motivados y participativos que se involucren y hagan suyos los cambios, complementan el papel de las instituciones y los incentivos hacia la transformación de la

12 En Re-Stating social and political change, Hay trazó la evolución del Estado británico, la ciudadanía, la crisis y del Thatcherismo. Por otra parte, el propio Jessop también ha perseguido tareas similares en diversas publicaciones. La globalización ha sido sometida a un escrutinio critico también. 
sociedad (STIGLITZ, 1998c). De este modo, y en virtud de la "participación y la propiedad", las dinámicas endógenas sociales del cambio dependerán de la función decisiva de los organismos para la intencionalidad, la indeterminación y la incertidumbre en los procesos.

Se debe reconocer que las instituciones pueden ser una condición necesaria, pero nunca una suficiente para el cambio, ya que las instituciones son también objeto de cambio en sí mismas, es importante tener en cuenta que la probabilidad de colapso también podría surgir. A medida que la complejidad de los sistemas y procesos se eleva, también lo hace la probabilidad de cambio, para lo cual procesamientos eficientes de información e intercambio son vitales para responder a los desafíos planteados por una posible catástrofe (DARK, 1998). Sin embargo, los problemas de asimetría e información incompleta tienden a ser más la regla que la excepción (AKERLOF, 1970; SPENCE, 1973; ROTHSCHILD; STIGLITZ, 1976). La información incompleta y asimétrica es bastante común para los actores tanto públicos como privados, y tiene consecuencias directas sobre los cursos de acción que decidan tomar. Por lo tanto, esto plantea un reto significativo a medida que aumentan los riesgos, las oportunidades para la innovación también aumentan, lo que potencialmente puede transformar y producir nuevos sistemas y alimentar a las nuevas tendencias y contra-tendencias. Claramente, una de las estrategias para difundir socialmente los nuevos patrones de interacción, o por la revelación y divulgación de los cursos de acción preferidos es el desarrollo de las redes. En la creación de redes, ya sea formal o informalmente, en una amplia gama de cuestiones, el carácter relacional de la interacción ayuda a la dinámica de convertirse en parte endógena de los actores, contribuyendo de esta manera hacia el interior de la propiedad, y cambiar la participación. Por lo tanto, la creación de redes proporciona los medios para dar respuestas flexibles e inter-organizacionales a las nuevas circunstancias. Por otra parte, la creación de redes implica la formulación y aplicación de estrategias en la acción. Los cursos de acción, a su vez, producen efectos directos y el aprendizaje estratégico para los actores, que tienen que hacer frente y adaptarse a consecuencias intencionales y no intencionales (HAY, 1998). Las redes de muchos tipos de estrategias de organización históricamente son recurrentes y familiares en todo el mundo, y alcanzan variados grados de complejidad en las diferentes sociedades, culturas e instituciones. Debido a su flexibilidad y funcionalidad, y el reconocimiento de los programas que son de importancia 
mutua o complementaria de sus miembros, las redes funcionan como nodos de coordinación de la acción colectiva (HAY, 1998; HAY; RICHARDS, 2000). La fácil aplicación horizontal es la ventaja de la red, ya que permite a sus participantes formular y aplicar estrategias que proporcionen, no sólo los efectos inmediatos directos para los cuales fue creada la red de origen, sino también de aprendizaje estratégico. Además, como algunos temas u objetivos pueden ser de mayor interés o de importancia, la formación de alianzas estratégicas se puede utilizar para impulsar la agenda común a seguir, y esto puede funcionar en beneficio de sus partes constitutivas. Es precisamente este carácter relacional y la sencillez para la formación, evolución, transformación y terminación de las redes que les da su flexibilidad en relación a los cambios sociales, económicos y políticos varios. Por lo tanto, planes y objetivos comunes estratégicos para una amplia variedad de temas puede ser establecida por la creación de redes (HAY, 1998; HAY; RICHARDS, 2000). En cuanto a una de las objeciones importantes a las redes, se ha argumentado que procesan inadecuadamente temas de inclusión y exclusión limitada. Es cierto que el alcance de las posibilidades de transformación mediante la creación de redes no puede ser extendido más allá de ciertos límites. Es evidente que algunos de los beneficios que no están directamente considerados se pueden lograr por los agentes que no están incluidos o no tomar parte directa en las prácticas de redes. Sin embargo, en este punto es importante hacer hincapié en la alternativa de la red sólo como un complemento a las fallas del mercado y las fallas del gobierno. No se pretende que este último pueda ser eliminado por el primero. De hecho, las redes pueden complementar otras formas de gobierno como los mercados y las jerarquías, y al hacerlo, el problema de la exclusión de la red puede ser tratada. Hay que tomar en cuenta que la dependencia excesiva de una sola forma de gobierno es problemática. Sin embargo, conseguir el equilibrio adecuado entre los mecanismos de gobernanza no es nada fácil y varía significativamente, dependiendo de las circunstancias particulares en que los agentes se encuentran.

\section{Observaciones finales}

El presente artículo constituye una modesta contribución a desarrollar el potencial argumentativo y explicativo de el enfoque estratégico relacional en contextos internacionales no típicamente asociados con economías 
desarrolladas. México como caso en cuestión proporciona una realidad social mestiza, condición que permite subrayar la sintonía de la filosofía realista crítica con la diversidad tanto de referentes teóricos, ideales y empíricos. Ello hace a todas luces evidente el amplio espectro de potenciales contribuciones que pueden esperarse del desarrollo tanto del realismo crítico como del SRA.

Reconociendo la ontología del realismo crítico mestizo, el SRA cuenta con una postura realista epistemológica. De esta última, el conocimiento se considera toda clase de práctica social adquirida principalmente a través de la actividad y la interacción, que se encuentra en contextos específicos y nunca se desarrolla en el vacío. Debido a su falibilidad y que el carácter cargado de teoría de la observación debe ser admitido, el motivo para adoptar un enfoque crítico no debería ser una sorpresa. Además, dado que la producción de conocimiento es una práctica social, la explicación y la comprensión de los fenómenos sociales involucra a los analistas en las evaluaciones críticas de la sociedad y la comprensión de su propio lugar dentro de la sociedad. Por lo tanto, la formulación de las críticas informadas no pueden ser evitadas.

El realismo es una filosofía de y para las ciencias sociales que establece una distinción entre las dimensiones transitivas e intransitivas del conocimiento. Por un lado, la dimensión intransitiva comprende objetos de la ciencia, tales como los fenómenos sociales o eventos políticos. Por otro lado, el dominio transitivo presta atención a la teoría y discursos, que a su vez también podrían ser tratados como objetos de estudio en sí mismos. Por otra parte, reconociendo que los contextos sociales se asemejan a los sistemas abiertos en los fenómenos sociales, políticos y económicos, presentan diferentes grados de complejidad, donde la identificación y evaluación de las conexiones, de las asociaciones formales o regularidades, resultan cruciales. De este modo, se hace uso de un método crítico que no se limita a describir lo observable, sino también lo inobservable de los fenómenos y examina las relaciones necesarias y contingentes, así como las asociaciones justificadas e injustificadas. Por lo tanto, el examen de las relaciones entre las estructuras, mecanismos y eventos es de vital importancia para el análisis de los procesos de cambio, lo que se suma a la importancia de prestar especial atención a los problemas de conceptualización y abstracción. Para el realismo crítico mestizo, el reconocimiento de que los procesos sociales se encuentran dentro de determinados contextos espacio-temporales no debe ser pasado por alto, como tampoco la necesidad de la especificidad histórica 
y geográfica podría contribuir a superar las concepciones interpretativas, y avanzar hacia las explicaciones causales, en lugar de regularidades formales de los fenómenos sociales.

La capacidad de la crítica realista, inspirada en el SRA para identificar y rastrear las relaciones causales resulta útil para explorar el carácter profundamente político de los procesos sociales de cambio. Dado que el enfoque es capaz de reconocer las relaciones entre los elementos materiales e ideacionales, por una parte, y las que existen entre los elementos estructurales y agenciales, por el otro, ofrece espacio para examinar las tendencias y contratendencias en que se basan los procesos.

Teniendo esto en cuenta, el Estado como un fenómeno policontextual y polivalente no puede desunirse del contexto social integrado en el que se encuentra. Debido a que se orienta a mantener y reproducir las condiciones para la acumulación de capital y la creación de riqueza, no puede ignorar un problema con los imperativos de legitimación. Por lo tanto, ocupa un lugar central y juega un papel crucial que ningún otro actor puede asumir. $\mathrm{Al}$ reconocer las fallas de mercado, debido a la asimetría de la información y la ineficiencia, el Estado todavía puede corregir las deficiencias de distribución y puede ser ayudado para aumentar los incentivos para la eficiencia. El hecho de que las instituciones tienden a persistir sin llegar a ser permanentes refleja la forma dinámica y fluida del Estado y su apariencia, que responde y es responsable de los cambios del entorno y condiciones. Sin embargo, el carácter socialmente integrado político y relacional de los procesos estatales, se renueva continuamente y se reconfigura, originándose en las interacciones entre los agentes de poder relacionales situados en su contexto, en lugar de ser simplemente un aspecto del poder del Estado. Por lo tanto, el Estado no puede erosionar el poder en relación con los actores porque no es suyo.

La sugerencia de Jessop sobre los tipos ideales altamente estilizados de la transición de un KWNS a un SWPR se centra en la subordinación de las políticas sociales a las políticas económicas, la escala geográfica o territorial de la operación y los medios que se utilizan para compensar los fallos del mercado.

Se sostiene que más allá de las características de estos tipos ideales, y su ajuste imperfecto con el caso mestizo mexicano, es que la fuerza de la utilidad teórica del SRA abre nuevas vías de investigación para el seguimiento de 
procesos. Tales procesos hacen hincapié en las cuestiones de economía política, como las experiencias de mercantilización, o temas socio-políticos, como la autonomía política y la democratización, y no pueden ser descontextualizados de su ubicación espacio-temporal.

Por otra parte, la influencia del realismo crítico en el SRA nos permite explorar la dinámica no estática que se convierte en propiedad de forma endógena, participación pro-activa y apropiación interna, donde hacer un cambio no sólo es posible sino también es viable. Dado que las instituciones son una condición necesaria pero nunca suficiente para el cambio social, la intencionalidad, la incertidumbre e imprevisibilidad, que las interacciones de los actores infunden en los procesos, afectan claramente la evolución de los resultados finales.

Sin embargo, haciendo uso de las herramientas teóricas de este enfoque, se ha logrado identificar que una de las principales estrategias para la apropiación y difusión del cambio es la creación de redes. Esto no es un pequeńo problema, ya que es capaz de crear y abrir opciones para los agentes situados que participan en las redes. Para la creación de redes con éxito, la definición de una agenda estratégica común que pueda guiar la interacción de los miembros y servir como una referencia de guía para evaluar el progreso, la realineación, el fracaso o el éxito es necesario. Redes no necesariamente significa un contacto limitado entre grupos específicos. Por el contrario, las redes se pueden ampliar a través de grupos de diferentes tipos, que presentan cursos de acción alternativos y ampliación de las ventanas de oportunidad para los involucrados. Su carácter puede ser económico, burocrático, industrial, electoral y así sucesivamente, dependiendo de los temas centrales acordados y establecidos en la agenda estratégica de las organizaciones.

\section{Referencias}

AKERLOF, G. A. The market for lemons: quality uncertainty and the market mechanism. The Quarterly Journal of Economics, v. 84, n. 3, p. 488-500, 1970.

ARCHER, M. et al. (Ed.). Critical realism: essential readings. London: Routledge, 1998.

BABB, S. Managing Mexico: economists from nationalism to neoliberalism. Princeton, NJ: Princeton University Press, 2001. 
BERTALANFFY, L. von. Teoría general de los sistemas: fundamentos, desarrollo, aplicaciones. México, FCE, 1986.

BHASKAR, R. A realist theory of science. London: Verso, 1975.

A realist theory of science. 3. ed. London: Verso, 1997.

. General introduction. In: ARCHER, M. et al. (Ed.). Critical realism: essential readings. London: Routledge, 1998.

. Dialectic: the pulse of freedom. London: Verso, 1993.

. Plato, etc: the problems of philosophy and their resolution. London: Verso, 1994.

Reclaiming reality: a critical introduction to contemporary philosophy. London: Verso, 1989.

Scientific realism and human emancipation. London: Verso, 1987.

The possibility of naturalism: a philosophical critique of the contemporary human sciences. London: Routledge, 1979.

The possibility of naturalism: a philosophical critique of the contemporary human sciences. 3. ed. London: Routledge, 1998.

BLAIKIE, N. Approaches to social enquiry. Cambridge: Polity, 1993.

CALVA, J. L. México más allá del neoliberalismo: opciones dentro del cambio global. México: Plaza y Janés, 2000.

CASAR, M. A. Las bases político-institucionales del poder presidencial en México. In: MAYERSERRA, C. E.; HERNÁNDEZ, B. N. (Ed.). Lecturas sobre el cambio político en México. México: CIDE: FCE, 2002. p. 41-78.

CIMOLI, M. (Ed.). Developing innovation systems: Mexico in a global context. London: Continuum, 2000.

CUADRA-MONTIEL, H. Demystifying globalization and the state: preliminary comments on recommodification, institutions and innovation. In: PACHURA, P. (Ed.). The systemic dimension of globalization. Croatia: InTech, 2011.

. Globalization and Re-Commodification in Mexico. In: (Ed.). Globalization Approaches to diversity. Croacia: InTech, 2012.

Incompleteness of Post-Washington consensus: a critique of macro-economic and institutional reforms. International Studies, v. 44, n. 2, p. 103-122, 2007. 
Social change in Mexico: re-politicizing the agenda of reform. International Review of Sociology - Revue Internationale de Sociologie, v. 19, n. 3, p. 411-432, 2009.

Where does Mexico stand? Interpreting NAFTA's regional scope and the FTAA Hemispheric Project. Norteamérica, v. 3, n. 1, p. 65-93, 2008.

DARK, K. R. The waves of time: long-term change and international relations. London: Continuum, 1998.

DOMINGO, P. Judicial independence: the politics of the Supreme Court in Mexico. Journal of Latin American Studies, v. 32, n.3 p. 705-735, setembro 2000.

DOMÍNGUEZ, J. I.; POIRÉ, A. (Eds). Towards Mexico's democratisation: parties, campaigns, elections and public opinion. London: Routledge, 1999.

DUSSEL PETERS, E. La economía de la polarización: teoría y evolución del cambio estructural de las manufacturas mexicanas (1988-1996). México: Universidad Nacional Autónoma de México and Editorial Jus, 1997.

Polarising Mexico: the impact of liberalisation strategy. Boulder, CO: Lynne Rienner, 2000.

MAYER-SERRA, C. E.; HERNÁNDEZ, B. N. La lógica del cambio político en México. In: ; _ (Ed.). Lecturas sobre el cambio político en México. México: CIDE: FCE, 2002. p. 7-38.

; (Ed.). Lecturas sobre el cambio político en México. México: CIDE: FCE, 2002.

FAJNZYLBER, F. Unavoidable industrial restructuring in Latin America. Durham, NC: Duke University Press, 1990.

GEREFFI, G. Mexico's "old" and "new" maquiladora industries: contrasting approaches to North American integration. In: OTERO, G. (Ed.). Neoliberalism revisited: economic restructuring and Mexico's political future. Boulder, CO: Westview, 1996. p. 85-105

; KORZENIEWICZ, M. (Ed.). Commodity chains and global capitalism. Westport, CT: Praeger, 1994.

; WYMAN, D. L. (Ed.). Manufacturing miracles: paths of industrialisation in Latin America and East Asia. Princeton, NJ: Princeton University Press, 1990.

GIUGALE, M. M.; LAFOURCADE, O.; NGUYEN, V. H. (Ed.). Mexico: a comprehensive development agenda for the new era. Washington, DC: The World Bank, 2001.

GRINDLE, M. S. Challenging the state: crisis and innovation in Latin America and Africa. Cambridge: Cambridge University Press, 1996. 
HANSEN, R. The politics of mexican development. Baltimore, MD: Johns Hopkins University Press, 1971.

HAY, C. Political analysis: a critical introduction. Basingstoke: Palgrave, 2002.

. Re-Stating social and political change. Buckingham: Open University Press, 1996.

. Structure and agency. In: MARSH, D.; STOKER, G. (Ed.). Theory and methods in political science. Basingstoke: Macmillan, 1995. p. 189-206.

The tangled webs we weave: the discourse, strategy and practice of networking. In: MARSH, D. (Ed.). Comparing Policy Networks. Buckingham: Open University Press, 1998. p. 33-52.

; RICHARDS, D. The tangled webs of Westminster and Whitehall: the discourse, strategy and practice of networking within the British core executive. Public Administration, v. 78, n. 1, p. $1-28,2000$.

HEIGL, M. C. An operationalization of the strategic-relational approach: the contested privatization of the mexican oil sector (1982-2006). Globalizations, v. 8, n. 1, p. 81-96, 2011.

JESSOP, B. From the KWNS to the SWPR. In: LEWIS, G.; GEWIRTZ, S.; CLARKE, J. (Ed.). Rethinking social policy. London: Sage, 2000.

State power: a strategic-relational approach. Cambridge: Polity, 2008.

State theory: putting the capitalist state in its place. Cambridge: Polity, 1990.

The capitalist state: marxist theories and methods. Oxford: Robertson, 1982.

The future of the capitalist state. Cambridge: Polity, 2002.

KEYNES, J. M. The general theory of employment, interest and money. London: Macmillan, 1964.

KRAUZE, E. Mexico: biography of power. A history of modern Mexico, 1810-1996. New York: HarperCollins, 1997.

LAWSON, T. Economics and reality. London: Routledge, 1997.

. Reorienting economics. London: Routledge, 2003.

LEVY, D. C. Mexico: sustained civilian rule without democracy. In: DIAMOND, L.; LINZ, J.; LIPSET, S. M. (Ed.). Politics in developing countries: comparing experiences with democracy. Boulder, CO: Lynne Rienner, 1990. p. 135-173.

; BRUHN, K. Mexico: the struggle for democratic development. Berkeley, CA: University of California Press, 2001. 
LINZ, J. The perils of presidentialism. Journal of Democracy, v. 1, n. 1, p. 51-69, 1990.

LUHMANN, N. La ciencia de la sociedad. México: Universidad Iberoamericana: Iteso: Anthropos, 1996.

. Sistemas sociales: lineamientos para una teoría general. Barcelona: Anthropos: Universidad Iberoamericana, 1998.

LUSTIG, N. Mexico: the remaking of an economy. 2. ed. Washington, DC: Brookings Institution, 1998.

MORRIS, S. D. Reforming the nation: Mexican nationalism in context. Journal of Latin American Studies, v. 31, n. 2, p. 363-397, abril 1999.

PECK, J.; TICKELL, A. Searching for a new institutional fix: the after-Fordist crisis and the globallocal disorder. In: AMIN, A. Post-Fordism: a Reader. Oxford: Blackwell, 1994.

POLANYI, K. The great transformation: the political and economic origins of our time. Boston, MA: Beacon Press, 1957.

REYNOLDS, C. W. The mexican economy: twentieth-century structure and growth. New Haven, CT: Yale University Press, 1970.

ROTHSCHILD, M.; STIGLITZ, J. E. Equilibrium in competitive insurance market: an essay on the economics of imperfect information. The Quarterly Journal of Economics, v. 90, n. 4, p. 629-649, 1976.

SANDOVAL BALLESTEROS, I. E. Hacia un enfoque "Estratégico-Relacional" del Estado: más allá del nuevo institucionalismo. Perfiles Latinoamericanos, n. 25, p. 217-235, dic. 2005.

SERRANO, M. (Ed.). Governing Mexico: political parties and elections. London: ILAS: University of London, 1998.

SERVILLO, L. A.; VAN DEN BROECK, P. The social construction of planning systems: a strategic-relational institutionalist approach. Planning Practice and Research, v. 27, n. 1, p. 4161, 2012.

SPENCE, M. Job marketing signalling. The Quarterly Journal of Economics, v. 87, n. 3, p. 355374, 1973.

STIGLITZ, J. E. Another century of economic science. The Economic Journal, v. 1, n. 404, p. 134-141, 1991.

Globalisation and its discontents. London: Allen Lane, 2002. 
STIGLITZ, J. E. More instruments and broader goals: moving toward the post-Washington consensus. Conferencia presentada en el Instituto Mundial de Investigación sobre Desarrollo Económico, Helsinki, 1998a.

On the economic role of the state. In: The economic role of the state. Oxford: Blackwell, 1989. p. 11-85.

STIGLITZ, J. E. Redefining the role of the state: what should it do? How should it do it? And how should these decisions be made? Conferencia presentada en el Décimo Aniversario del Instituto de Investigación del Ministerio de Industria y Comercio Internacional, Tokyo, 1998b.

. The role of the state in financial markets. Washington, DC: The World Bank, Report, n. $14.334,1994$.

STIGLITZ, J. E. Towards a new paradigm for development: strategies, policies and processes. The 1998 Prebisch Lecture at UNCTAD, Geneva, World Bank, 1998c.

VREELAND, J. R. The IMF and economic development. Cambridge: Cambridge University Press, 2003.

WARD, P. M.; RODRÍGUEZ, V. E. New federalism, intra-governmental relations and co-governance in México. Journal of Latin American Studies, v. 31, n. 3, p. 673-710, Setembro 1999.

WATSON, M. The political discourse of globalisation: globalising tendencies of self-induced external enforcement mechanisms. Birmingham. Tese (Doutorado em Filosofia). University of Birmingham, 2000.

WEBER, M. Economy and society: an outline of interpretive sociology. Berkeley, CA: University of California Press, 1979.

WORLD BANK. World development report 1997: the state in a changing world. Washington DC: World Bank, 1997.

Recebido em: 13/042014

Aprovado em: 23/07/2014

\section{Mestizo critical realism: an analysis of Mexico from the strategic-relational approach}

\section{Abstract}

This article opens with a brief analysis of key features of the Mexican semi-authoritarian regime. It then moves to a discussion of the critical realist positions and features that inform the strategic- 
relational approach (SRA). Attention is paid to social interactions and causal relations that enable the SRA to trace patterns of punctuated evolution and to highlight the processes of transformation. Since ideal types serve to highlight key characteristics in specific phenomena, processes and actors, some features of ideal types of the state and of the transition from one type to another are also discussed. In particular, attention is paid to the Keynesian Welfare National State (KWNS) and to the Schumpeterian Workfare Post-national Regime (SWPR) ideal types elaborated by Jessop. For it is contended that the specific features of these ideal types could be of great help in broadening the debate on economic restructuring and political reforms in countries such as Mexico. Moreover, the SRA provides an insight into the endogenous features of social change and stresses the importance of networking for a strategic agenda as well. For the never-static dynamics of the processes of change the role of situated agents in context is fundamental, as it injects intentionality and acknowledges the contingency of the conditions that surround them.

Keywords: Critical realism. Strategic-relational approach. Structure and agency. Mexico. KWNS and SWPR 